\title{
Rent seeking and aid effectiveness
}

\author{
Roland Hodler
}

Published online: 13 September 2006

(c) Springer Science + Business Media, LLC 2006

\begin{abstract}
We introduce foreign aid and a rent seeking contest for public funds into the Barro (JPE 1990) growth model. We find that aid effectiveness depends on fiscal policies, the level of aid inflows and the quality of institutions that restrict appropriation of public funds by rent seeking agents. These results can be shown to be consistent with the best established findings in the empirical literature on aid effectiveness. Rent seeking may thus indeed be a major determinant of aid effectiveness. We further discuss how aid effectiveness depends on the way foreign aid is disbursed and on the determinants of institutional quality.
\end{abstract}

Keywords Foreign aid · Growth · Rent seeking

JEL Classification F35 - D72 - D9 - H2

\section{Introduction}

Aid effectiveness, i.e., the effect of foreign aid on economic growth, varies substantially across countries. The quest for the cause of this variation dominates the recent empirical literature on foreign aid. Arguably, the three best established findings suggest that foreign aid is more effective, (i) the better the policy environment, (ii) the lower the level of aid inflows, and (iii) outside the tropics than within. A priori, these findings do not seem closely related to one another. In this paper, we however present a simple growth model with foreign aid and a rent seeking contest for public funds that can simultaneously account for these three different findings. This suggests that rent seeking may be a major determinant of aid effectiveness.

R. Hodler $(\square)$

University of Bern, Department of Economics, Schanzeneckstrasse 1, CH-3001 Bern, Switzerland e-mail: roland.hodler@vwi.unibe.ch 
Our model extends the Barro (1990) growth model with a productive public sector in two directions: First, public funds are not solely financed by tax revenues, but also by foreign aid inflows. Second, there is a rent seeking contest for parts of the public funds, and only the remaining funds are used to provide productive public goods. ${ }^{1}$ In this model, foreign aid has a positive effect on growth by increasing the provision of productive public goods, but a negative effect by causing people to channel resources away from productive activities to rent seeking. The net effect of foreign aid on growth depends on fiscal policies, on the level of aid inflows and on the quality of institutions that restrict appropriation of public funds by rent seekers. We argue that these results are consistent with the empirical findings mentioned above. We refer to the recent literature that finds institutional quality to depend on climate- and healthrelated circumstances (Acemoglu, Johnson, and Robinson, 2001) when arguing that our model can explain why aid is more effective outside the tropics than within. The positive effect of foreign aid on rent seeking might thus indeed be a major reason for low aid effectiveness (i) in bad policy environments, (ii) in countries with large aid inflows, and (iii) in tropical countries in which institutional quality tends to be poor.

The idea that foreign aid may lead to rent seeking, and that rent seeking, in turn, may lower aid effectiveness, goes back at least to Bauer (1981). While there is substantial support for a negative effect of corruption and rent seeking on economic growth (see, e.g., Knack and Keefer (1995) and Mauro (1995)), there is also some evidence that foreign aid causes rent seeking: Svensson (2000) finds that foreign aid tends to increase corruption in ethnically fractionalized countries, which might be particularly vulnerable to rent seeking. In addition, Knack (2001) finds that an increase in foreign aid leads to a drop in the International Country Risk Guide's quality of governance index, which includes bureaucratic quality, corruption and the rule of law. We agree with Knack that rent seeking is a very likely channel through which foreign aid could lower the quality of governance. We see the consistency between the results from our model on rent seeking and growth, on the one hand, and the empirical evidence on aid effectiveness, on the other hand, as further indirect evidence that foreign aid may lead to rent seeking, which, in turn, affects aid effectiveness.

Our model is most closely related to the theoretical contributions of Svensson (2000) and Dalgaard, Hansen, and Tarp (2004). Svensson presents a repeated game in which the direct positive effect of higher aid payments on the provision of public goods may be offset by an increase in rent seeking activities. Our model differs mainly as it is based on a standard growth model, and as it leads to results that can be shown to be consistent with the empirical evidence on aid effectiveness. Dalgaard, Hansen, and Tarp (2004) present an overlapping generation model in which the growth effect of foreign aid depends on how much aid is expropriated, i.e., disappears, and on how the remaining aid is distributed between the young and the old. Their general model can certainly be interpreted as a model of rent seeking, foreign aid and growth. The main difference of our model is that the agents' resource allocation to rent seeking and productive activities is endogenous. An increase in aid inflows thus causes more intensive rent seeking in our model.

\footnotetext{
${ }^{1}$ Mauro (2004) has first introduced a rent seeking contest for public funds into the Barro model. 
Furthermore, Lane and Tornell (1996) and Tornell and Lane (1999) rely on rent seeking to explain why another type of windfall gains, terms of trade windfalls, often lead to low growth rates. More generally, our paper relates to the theoretical literature on the interrelations between rent seeking and corruption, on the one hand, and growth, on the other. Major contributions include Gelb, Knight, and Sabot (1991), Murphy, Shleifer, and Vishney (1991), Tornell and Velasco (1992), Sturzenegger and Tommasi (1994), Benhabib and Rustichini (1996), Ades and di Tella (1997), Bardhan (1997), Tornell (1997), Ehrlich and Lui (1999), Barreto (2000), Mauro (2004), and Ellis and Fender (2006). ${ }^{2}$ These contributions, however, do not assess the effects of foreign aid or other windfall gains on rent seeking, corruption and growth.

The remainder of this paper is organized as follows: In Section 2, we briefly review the recent empirical literature on aid effectiveness. In Section 3, we present our baseline model. We keep it deliberately simple to focus on the main linkages between foreign aid, rent seeking and economic growth. After presenting our results, we show that they are consistent with the evidence on aid effectiveness discussed in Section 2. In Section 4, we then discuss the robustness of our results. In particular, we show how they depend on the aid pattern, on the determinants of institutional quality, and on whether foreign aid is provided on a conditional basis. These discussions yield further interesting insights into the circumstances under which foreign aid may work particularly well and on those under which foreign aid might be doomed to fail. We conclude in Section 5.

\section{Empirical evidence on aid effectiveness}

The recent empirical literature on aid effectiveness offers several explanations why the effect of foreign aid on economic growth may vary across countries. In this section, we briefly describe the three arguably best established findings. ${ }^{3}$

The best known study on aid effectiveness is certainly Burnside and Dollar (2000). They construct a policy index and add an aid-policy interaction term to the independent variables. They find that foreign aid has a positive effect on growth, but only in countries with good policies. While Collier and Dollar (2002) confirm this finding, its robustness has been questioned by Dalgaard and Hansen (2001), Hansen and Tarp (2001), Lensink and White (2001), Easterly (2003), Easterly, Levine, and Roodman (2004), Roodman (2004), and others. Nevertheless, the view that aid works only in good policy environments has strongly influenced policymakers and aid agencies (Easterly, 2003).

Another well known finding is due to Dalgaard and Hansen (2001), Hansen and Tarp (2001), and Lensink and White (2001): These studies suggest that the growth effect of foreign aid varies across countries because of decreasing returns to foreign aid. In particular, they show that a specification with aid squared as independent variable is statistically superior to a specification with an aid-policy interaction term, and they find that the marginal growth effect of foreign aid is initially positive, but decreasing

\footnotetext{
${ }^{2}$ See Aidt (2003) for a recent survey of the theoretical literature on corruption.

${ }^{3}$ See Roodman (2004) for a more detailed account of these and some further findings on aid effectiveness.
} 
in the level of aid inflows. Lensink and White (2001), but not the two other studies, emphasize that the marginal growth effect becomes even negative at high levels of aid inflows. $^{4}$

In a recent study, Dalgaard, Hansen, and Tarp (2004) find that foreign aid is effective outside the tropics, but not within the tropics. They show that a specification with an aid-tropics interaction term is statistically superior to specifications with either an aid-policy interaction term or aid squared. They provide two possible explanations for their finding: The first suggests that aid effectiveness may directly depend on the climate. It has been argued by Sachs and his coauthors (e.g., Bloom and Sachs (1998), Gallup, Sachs, and Mellinger (1999), and Sachs (2001)) that tropical countries tend to grow slower than countries with a more temperate climate because of, among other things, lower agricultural productivity and a higher burden of diseases such as malaria. For the same reasons, foreign aid could have a stronger effect on growth in countries with a temperate climate than in tropical countries.

The second explanation of Dalgaard, Hansen, and Tarp (2004) suggests that aid effectiveness may depend on institutional quality. Acemoglu, Johnson, and Robinson (2001) provide evidence that climate and disease burden affect institutions. In particular, they show that European colonial powers were likely to implement good institutions in places with a temperate climate and low settler mortality, where many Europeans wanted to settle, but to implement extractive institutions in places with high settler mortality, which were usually in the tropics. As institutional quality tends to be highly persistent, former colonies with a temperate climate have on average still better institutions than former colonies in the tropics. Foreign aid may therefore be more effective outside the tropics than within because countries with a temperate climate tend to have better institutions, and because better institutions may strengthen the positive effect of foreign aid on growth. Personally, we consider this second explanation to be more plausible than the first one. This assessment is consistent with recent evidence by Acemoglu, Johnson, and Robinson (2001), Easterly and Levine (2003), and Rodrik, Subramanian, and Trebbi (2004) showing that institutional quality-instrumented by settler mortality-has a much stronger effect on growth than geographical variables. $^{5}$

Roodman (2004) thoroughly checks the robustness of the three presented and some further findings of the recent empirical literature on aid effectiveness. He finds the most robust finding to be that aid works only outside the tropics and the second most robust that there are decreasing returns to aid. We later show that our model can account for both of these findings as well as for the less robust, but very influential Burnside-Dollar finding.

\footnotetext{
${ }^{4}$ It is almost self-evident that returns to aid are decreasing if aid is used to finance capital or productive public goods, and if returns to capital and productive public goods are decreasing. However, decreasing returns to capital and productive public goods cannot explain negative returns to aid. Lensink and White (2001) argue that negative returns to aid can result from limited absorptive capacity in poor recipient countries. Moreover, Dalgaard and Hansen (2001) present a model in which consumption of aid can also lead to decreasing returns to aid.

${ }^{5}$ Sachs (2003) doubts the robustness of these findings. 


\section{The baseline model}

In this section, we present the baseline model, which is based on the Barro (1990) growth model with a productive public sector. We keep the baseline model deliberately simple to focus on the main linkages between foreign aid, rent seeking and economic growth. The roles of some assumptions, which are either crucial for our results or which might appear at odds with empirical observations, are discussed in Section 4. We start this section here by presenting the setting of our baseline model. We then derive how agents optimally allocate their time to rent seeking and productive activities, and we solve the agents' intertemporal optimization problem. Afterwards, we analyze the effects of fiscal policies, foreign aid and institutions that restrict appropriation by rent seekers on the growth rate and on aid effectiveness, i.e., the growth effect of foreign aid. We further compare our results to the empirical findings presented in the previous section.

\subsection{Setting}

Given is a country populated by a measure-one continuum of agents. This country or its government, respectively, receives aid payments $F_{t}$ from foreign donors at each date $t$. We assume that these aid payments are proportional to the recipient country's aggregate output $y_{t}$, i.e., $F_{t}=f y_{t}$ with $f \geq 0$, and that they are fungible, which implies that there are no binding conditions attached to these payments. The former assumption, which satisfies the more recent claim that donors should reward recipient countries that promote growth seriously and successfully (see, e.g., Easterly (2001)), is made for analytical tractability. We discuss in Section 4.1 how our results may change if $F_{t} / y_{t}$ were decreasing in $y_{t}$, as it tends to be the case in reality. The fungibility assumption is in line with the findings of Feyzioglu, Swaroop, and Zhu (1998) and the World Bank (1998), which concludes that aid appears to be largely fungible. We nevertheless discuss the potentially very positive effects of conditional aid in Section 4.4.

Besides foreign aid, the government receives a fixed share $\tau \in[0,1)$ of the production $y_{i t}$ of each agent $i$ at each date $t$. Even though the share $\tau$ is subsequently called tax rate, it stands more generally for any kind of revenues the government collects from agents engaging in productive activities.

As in the Barro model, the government's budget is balanced at all times. Public funds are thus given by

$$
p_{t}=(\tau+f) y_{t}
$$

where $y_{t}=\int_{0}^{1} y_{i t} d i$. But, unlike in the Barro model, the share $\phi \in[0,1)$ of these funds, i.e.,

$$
r_{t}=\phi p_{t}
$$

is appropriated by agents engaging in rent seeking activities. Since the share rent seekers may in reality be able to appropriate from public funds is likely to decrease in 
institutional quality, e.g., in the prevalence of the rule of law or in bureaucratic quality, ${ }^{6}$ we regard $\phi$ as an inverse measure of institutional quality: The higher $\phi$ is, the poorer are the institutions that restrict appropriation of public funds by rent seekers. For the moment, we assume that institutional quality is independent of aggregate rent seeking efforts, and that rent seekers can appropriate the same shares of aid and tax revenues. We discuss in Sections 4.2 and 4.3, respectively, how dropping these assumptions affects our results.

The public funds that are not appropriated by rent seekers are converted into productive public goods $g_{t}$, i.e.,

$$
g_{t}=(1-\phi) p_{t}
$$

Each agent $i$ seeks to maximize her utility

$$
U_{i}=\int_{0}^{\infty} \frac{c_{i t}^{1-\sigma}}{1-\sigma} \exp (-\rho t) d t
$$

where $c_{i t}$ denotes her consumption at date $t, \rho>0$ her discount rate and $\sigma>0$ the inverse of the intertemporal elasticity of substitution. Each agent $i$ can generate income by producing output $y_{i t}$ and by seeking rents $r_{i t}$. She can use her income for current consumption $c_{i t}$ and to accumulate capital $k_{i t}$, which is a broad aggregate including human as well as physical capital. Each agent $i$ is endowed with one time unit at each date $t$ and with an initial capital stock $k_{i 0}=k_{0}>0$.

The production technology is given by

$$
y_{i t}=A k_{i t}^{1-\alpha}\left(l_{i t} g_{t}\right)^{\alpha} \text {, }
$$

where $l_{i t}$ denotes the labor input of agent $i$ at date $t$. We assume $\alpha \in(0,1 / 2)$ implying that capital is more important for production than public goods and labor are. ${ }^{8}$

The rent appropriation technology is such that agent $i$ can appropriate the rent

$$
\begin{aligned}
r_{i t} & =r_{t} \quad \text { if } e_{j t}=0 \text { for all agents } j \\
& =\frac{e_{i t}}{e_{t}} r_{t} \quad \text { otherwise, }
\end{aligned}
$$

where $e_{i t}=1-l_{i t}$ denotes the rent seeking effort of agent $i$ and $e_{t}=\int_{0}^{1} e_{j t} d j$ the aggregate rent seeking effort. ${ }^{9}$

\footnotetext{
${ }^{6}$ This is consistent with the observation that corruption tends to be high in places in which bureaucratic quality is poor and the rule of law weak (see, e.g., Knack and Keefer (1995), or Mauro (1995)).

${ }^{7}$ There is no rent seeking for public goods. This assumption is particularly unrestrictive if public goods are nonrival and nonexcludable.

${ }^{8}$ The assumption that the returns to human and physical capital exceed the returns to labor is consistent with the findings of Mankiw, Romer, and Weil (1992).

${ }^{9}$ This rent appropriation technology corresponds to Grossman's (2001) technology for appropriation from a common pool. It closely resembles a Tullock (1980) rent seeking contest success function.
} 
It follows that the disposable income of agent $i$ at date $t$ is

$$
m_{i t}=(1-\tau) y_{i t}+r_{i t}=(1-\tau) A k_{i t}^{1-\alpha}\left(l_{i t} g_{t}\right)^{\alpha}+\frac{e_{i t}}{e_{t}} r_{t}
$$

We next look at the two different decisions each single agent must take at each date $t$. First, we analyze how she chooses to allocate her time to rent seeking and productive activities. Second, we derive her optimal consumption-saving decision.

\subsection{Effort choices}

In this section, we derive the effort choice that maximizes the disposable income $m_{i t}$ of agent $i$. Following the literature on rent seeking contests, we thereby assume that agents cannot cooperate. ${ }^{10}$

When maximizing her disposable income $m_{i t}$, given by Eq. (7), agent $i$ takes public goods $g_{t}$, the aggregate rent seeking effort $e_{t}$, the funds $r_{t}$ that can be appropriated and her current capital stock $k_{i t}$ as given. She chooses the rent seeking effort $e_{i t}$ that satisfies the first-order condition

$$
\frac{r_{t}}{e_{t}}=\frac{(1-\tau) \alpha A k_{i t}^{1-\alpha} g_{t}^{\alpha}}{\left(1-e_{i t}\right)^{1-\alpha}} .
$$

It follows from condition (8) and $k_{i 0}=k_{0}$ that each agent $i$ chooses the same rent seeking effort $e_{i 0}^{*}=e_{0}^{*}$ at date 0 . Thus, all agents produce the same output $y_{i 0}=y_{0}$ and seek the same rent $r_{i 0}=r_{0}$. They also accumulate the same amount of capital. Hence, they choose again the same rent seeking effort in the subsequent period. This argument, which could be repeated ad infinitum, implies that $e_{i t}^{*}=e_{t}^{*}, k_{i t}=k_{t}$ and $y_{i t}=y_{t}$ hold for all $i$ and $t$.

We can thus rewrite first-order condition (8) as

$$
\frac{r_{t}}{e_{t}^{*}}=\frac{(1-\tau) \alpha y_{t}}{1-e_{t}^{*}} .
$$

Inserting Eqs. (1) and (2) and then solving for $e_{t}^{*}$ implies that each agent's optimal rent seeking effort is

$$
e^{*}=\frac{\phi(\tau+f)}{(1-\tau) \alpha+\phi(\tau+f)}
$$

at each date $t$. It increases in the share $\phi$ of public funds $p_{t}$ that rent seekers can appropriate, in the tax rate $\tau$ and in the aid ratio $f$. Each agent's optimal labor effort is $l^{*}=1-e^{*}$.

The rent appropriation technology (6) and $e_{i t}^{*}=e_{t}^{*}$ imply that each agent $i$ can extract a rent $r_{i t}=r_{t}$ at each date $t$.

\footnotetext{
${ }^{10}$ Note that it would always be in the agents' interest to coordinate on zero rent seeking if a commitment technology were available.
} 


\subsection{Consumption-saving decisions}

In this section, we look at the agents' consumption-saving decisions. We therefore solve the intertemporal optimization problem of a single representative agent (and omit agent indices).

This agent maximizes her utility $U$, given by utility function (4), subject to her initial capital endowment $k_{0}$ and the capital accumulation constraint

$$
\frac{d k_{t}}{d t}=(1-\tau) A k_{t}^{1-\alpha}\left(l^{*} g_{t}\right)^{\alpha}+r_{t}-c_{t}-\delta k_{t},
$$

where $\delta$ denotes the depreciation rate. Thereby, she takes public goods $g_{t}$ and aggregate rents $r_{t}$ again as given. Maximization yields the consumption growth rate

$$
\gamma_{t}=\frac{1}{\sigma}\left[(1-\tau) \alpha A\left(\frac{l^{*} g_{t}}{k_{t}}\right)^{\alpha}-\delta-\rho\right] \text {. }
$$

Equations (1), (3) and (5) imply

$$
\frac{g_{t}}{k_{t}}=\left[A(1-\phi)(\tau+f)\left(l^{*}\right)^{\alpha}\right]^{\frac{1}{(1-\alpha)}} .
$$

Hence, the consumption growth rate can be rewritten as

$$
\gamma=\frac{1}{\sigma}\left\{(1-\tau) \alpha A^{\frac{\alpha}{(1-\alpha)}}\left[(1-\phi)(\tau+f) l^{*}\right]^{\frac{\alpha}{(1-\alpha)}}-\delta-\rho\right\} .
$$

Given the standard assumption that utility is bounded, $\rho>(1-\sigma) \gamma$, capital $k_{t}$, output $y_{t}$, public funds $p_{t}$, public goods $g_{t}$ and rents $r_{t}$ grow at the constant rate $\gamma$ as well.

Equation (14) implies that the growth rate $\gamma$ increases in the agents' labor effort $l^{*}$. The agents' effort choices must therefore be taken into account when discussing how $\gamma$ depends on $\phi, \tau$ and $f$.

\subsection{Determinants of growth and aid effectiveness}

In this section, we first analyze how the growth rate $\gamma$ depends on institutional quality $\phi$, the tax rate $\tau$ and the aid ratio $f$. We then discuss how these parameters affect aid effectiveness, i.e., $\partial \gamma / \partial f$. We find that our results are consistent with the evidence on aid effectiveness presented in Section 2.

A decrease in institutional quality, i.e., an increase in the share $\phi$ of the public funds that rent seekers can appropriate, lowers the provision of productive public goods $g_{t}$ and decreases labor inputs $l^{*}$, as rent seeking becomes relatively more attractive. Since both these changes lower the incentive to accumulate capital, the growth rate $\gamma$ strictly decreases in $\phi$.

An increase in the tax rate $\tau$ has three different effects on the incentive to accumulate capital $k_{t}$ and, therefore, on the growth rate $\gamma$ : First, a positive effect as it increases the provision of productive public goods $g_{t}$. Second, a direct negative effect as it lowers the return on investments. Third, an indirect negative effect as it lowers labor inputs 
$l^{*}$ (since a tax increase lowers the return on labor and increases the return on rent seeking). It follows from Eqs. (10) and (14) that

$$
\frac{\partial \gamma}{\partial \tau}=\frac{\alpha(\gamma \sigma+\delta+\rho)}{(1-\alpha) \sigma}\left[\frac{1}{\tau+f}-\frac{1-\alpha}{(1-\tau) \alpha}+\frac{\epsilon_{\tau}}{\tau}\right]
$$

with

$$
\epsilon_{\tau} \equiv \frac{\partial l^{*}}{\partial \tau} \frac{\tau}{l^{*}}=\frac{-(1+f) \phi \tau}{(1-\tau)[(1-\tau) \alpha+\phi(\tau+f)]}<0 .
$$

The three effects mentioned above can be seen in the brackets of Eq. (15).

Let us briefly discuss the growth maximizing tax policy, i.e., $\tau^{*}=\operatorname{argmax}_{\tau} \gamma$. Subsequently, we call $\tau^{*}$ the optimal tax rate. Remember that $\tau^{*}=\alpha$ in the original Barro model, where $f=0$ and $\phi=0$. Suppose now that there is foreign aid, but no appropriation of aid inflows or other public funds by rent seekers. It directly follows from Eq. (15) and the constraint $\tau^{*} \in[0,1)$ that $\tau^{*}=\max \{\alpha-(1-\alpha) f, 0\} \leq \alpha$ when $\phi=0$. Hence, $\partial \tau^{*} / \partial f<0$ if $\tau^{*}>0$. Foreign aid reduces the optimal tax rate $\tau^{*}$ since aid-financed public goods lower the (marginal) return to tax-financed public goods and, thus, the positive effect of high tax rates. When $\phi>0, \tau^{*}$ can no longer be derived explicitly; we thus depict $\tau^{*}$ as a function of $f$ and $\phi$ in Fig. 1. This figure shows that foreign aid has also a negative effect on the optimal tax rate $\tau^{*}$ in presence of rent seeking, i.e., if $\phi>0$. Figure 1 further shows that the share $\phi$ of public funds that rent seekers can appropriate has in itself a negative effect on the optimal tax rate $\tau^{*}$. The main reason is that an increase in $\phi$ lowers the positive effect of taxation on the provision of productive public goods $g_{t}$. Hence, foreign aid and appropriation of public funds by rent seekers both reduce the optimal tax rate $\tau^{*}$, which thus becomes smaller than $\alpha$ and even non-positive if aid inflows are sufficiently high. ${ }^{11}$

We now turn to the discussion of aid effectiveness and its determinants. In our baseline model, an increase in the aid ratio $f$ has two effects on the growth rate $\gamma:{ }^{12}$ A positive effect because higher aid payments increase the provision of productive public goods $g_{t}$, and a negative effect because higher aid payments increase rent seeking efforts $e^{*}$. It follows from Eqs. (10) and (14) that

$$
\frac{\partial \gamma}{\partial f}=\frac{\alpha(\gamma \sigma+\delta+\rho)}{(1-\alpha) \sigma}\left[\frac{1}{\tau+f}+\frac{\epsilon_{f}}{f}\right]
$$

with

$$
\epsilon_{f} \equiv \frac{\partial l^{*}}{\partial f} \frac{f}{l^{*}}=\frac{-\phi f}{(1-\tau) \alpha+\phi(\tau+f)}<0 .
$$

\footnotetext{
11 These results hold for any $\alpha$.

${ }^{12}$ When analyzing the effect of foreign aid on growth, we assume that a change in aid does neither affect $\tau$, nor $\phi$. The former is consistent with the finding of Feyzioglu, Swaroop, and Zhu (1998, p. 27) "that a dollar given in official development assistance to developing countries does not lead to a tax relief effect." Moreover, it seems unlikely that foreign aid has a direct effect on $\phi$; it may however have an indirect effect through rent seeking. This possibility is discussed in Section 4.2.
} 


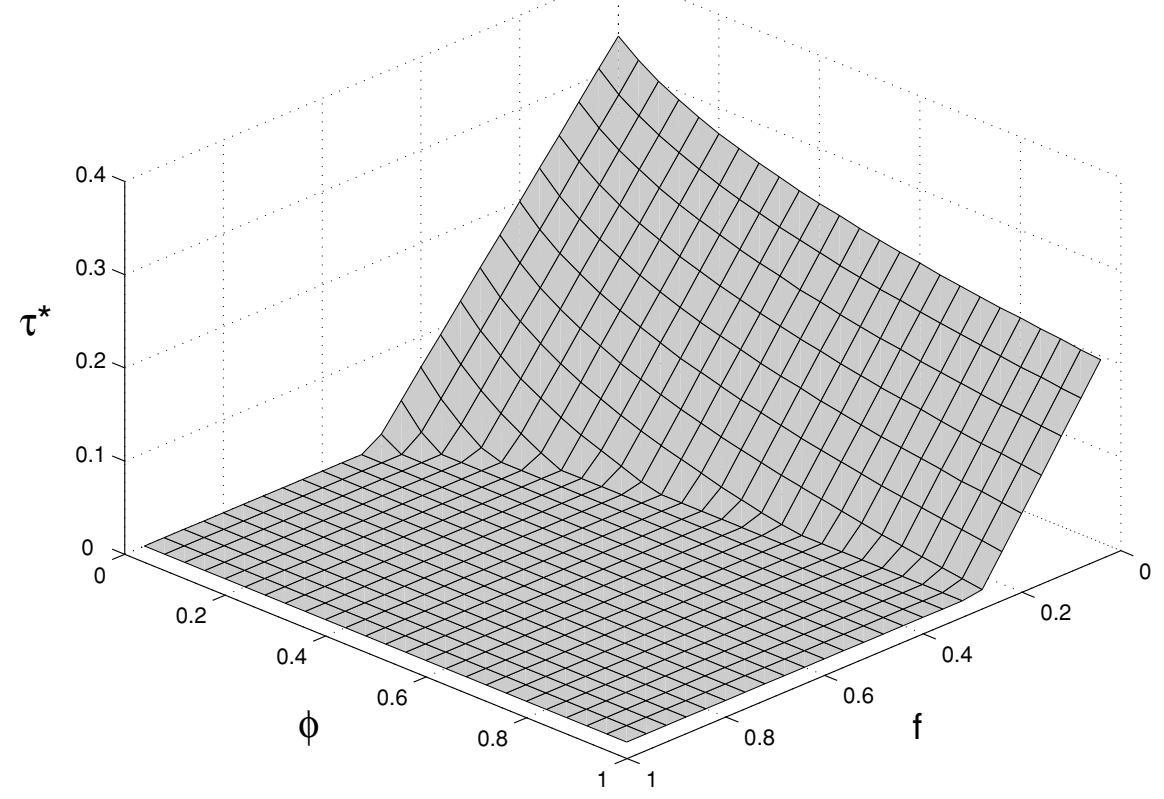

Fig. 1 The optimal tax rate $\tau^{*}$ as a function of $\phi$ and $f$ (given $\alpha=1 / 3$ )

The two effects mentioned above can be seen in the brackets of Eq. (17). It can easily be shown that the positive effect dominates. Hence, foreign aid raises growth, i.e., $\partial \gamma / \partial f>0$. This result however could change, as we show in Section 4.2, if an increase in aid and the associated rise in rent seeking impaired institutional quality. Even though the growth rate $\gamma$ always increases in $f$ in this baseline version of the model, the magnitude of this effect strongly depends on the tax rate $\tau$, the aid ratio $f$ itself and the institutional quality parameter $\phi$. In particular, it holds (i) that $\partial^{2} \gamma /(\partial f \partial \tau)<0$, (ii) that $\partial^{2} \gamma /\left(\partial f^{2}\right)<0$, and (iii) that $\partial^{2} \gamma /(\partial f \partial \phi)<0 .{ }^{13}$ In the remainder of this section, we provide the intuition for these three results, and we show that they are consistent with the three empirical findings on aid effectiveness discussed in Section 2.

Our first result on aid effectiveness, $\partial^{2} \gamma /(\partial f \partial \tau)<0$, states that foreign aid is the less effective, the more the government taxes agents engaging in productive activities. There are two reasons for this result: First, higher taxation lowers the (marginal) returns to aid-financed public goods by increasing the provision of tax-financed public goods. Second, higher taxation lowers the agents' labor inputs $l^{*}$ and, consequently, the realized returns to all types of public goods $g_{t}$. While aid effectiveness is always maximized by $\tau=0$, the growth maximizing tax rate $\tau^{*}$ is equal to zero, as seen before, if and only if $f$ is sufficiently high. Given sufficiently high aid inflows, growth and aid effectiveness are thus both maximized by the same tax policy: $\tau=0$. Given relatively low aid inflows, the growth maximizing tax rate $\tau^{*}$ exceeds the rate that maximizes

\footnotetext{
${ }^{13}$ These results are derived in the appendix. 
aid effectiveness, but high tax rates $\tau$ still hurt both, growth and aid effectiveness. Remember that Burnside and Dollar (1999) find foreign aid to be more effective, the better policies, including fiscal policies, are. Our results are thus roughly in line with the influential, but much challenged finding of Burnside and Dollar. ${ }^{14}$

Our second result on aid effectiveness, $\partial^{2} \gamma / \partial f^{2}<0$, states that the growth effect of foreign aid decreases in the level of aid inflows. In our model, there are two reasons for this decrease: First, foreign aid is partly used to finance productive public goods $g_{t}$, and the returns to these goods are decreasing. Second, higher aid payments increase the time agents devote to rent seeking and lower their labor inputs $l^{*}$. The result of a decreasing growth effect of foreign aid is perfectly in line with the empirical findings of Dalgaard and Hansen (2001), Hansen and Tarp (2001), and Lensink and White (2001). It might thus indeed be rent seeking and decreasing returns to productive public goods that cause decreasing returns to foreign aid. ${ }^{15}$

Our third result on aid effectiveness, $\partial^{2} \gamma /(\partial f \partial \phi)<0$, states that the growth effect of foreign aid increases in the quality of the institutions that (should) restrict rent seeking. The main reason for this result is that the positive effect of foreign aid on the provision of productive public goods $g_{t}$ increases in institutional quality, i.e., it decreases in $\phi$. Remember that a plausible, if not the most plausible, interpretation of the finding of Dalgaard, Hansen, and Tarp (2004) is that foreign aid is more effective in countries with good institutions, which tend to be located outside the tropics, than in countries with poor institutions, which tend to be located within the tropics. Hence, our result that aid effectiveness depends positively on institutional quality is consistent with this interpretation of the robust finding of Dalgaard and his coauthors.

\section{Discussion}

In this section, we discuss how the results from our baseline model depend on some particular assumptions we made. First, we investigate what results may change if the aid ratio $F_{t} / y_{t}$ is no longer constant, but decreasing in the recipient country's output $y_{t}$. Second, we look how our results may change if the share $\phi$ of the public funds that rent seekers can appropriate is no longer exogenous, but increasing in aggregate rent seeking activities. Third, we discuss how our results change if rent seekers can appropriate different shares from aid and tax revenues. Fourth, we focus on the potential effect of foreign aid that is truly conditional rather than fungible.

\subsection{Aid pattern}

For analytical tractability, the ratio of the aid payments $F_{t}$ to the recipient country's output $y_{t}$ is assumed to be constant in the baseline model. In reality, however, $F_{t} / y_{t}$

\footnotetext{
${ }^{14}$ Given institutional quality is seen as a function of current and past policies, as proposed by Rodrik, Subramanian, and Trebbi (2004), the result that $\partial^{2} \gamma /(\partial f \partial \phi)<0$ also suggests that aid effectiveness depends positively on the policy environment.

${ }^{15}$ Remember that Lensink and White (2001) find negative returns to foreign aid at high aid levels. Decreasing returns to productive public goods cannot explain this finding, while rent seeking can potentially explain it, at least in the modified version of the model presented in Section 4.2.
} 
tends to decrease in $y_{t}$. We therefore assume in this section that $F_{t} / y_{t}=f\left(y_{t}\right)$ with $\partial f\left(y_{t}\right) / \partial y_{t}<0 .{ }^{16}$

As a direct consequence, the agents' effort choices and the consumption growth rate $\gamma_{t}$ depend now on output $y_{t}$ : In analogy to Eq. (10), the agents' optimal rent seeking effort is now (implicitly) determined by

$$
e_{t}^{*}=\frac{\phi\left[\tau+f\left(y_{t}\right)\right]}{(1-\tau) \alpha+\phi\left[\tau+f\left(y_{t}\right)\right]},
$$

and, hence, decreasing in $y_{t}$. Similarly, the consumption growth rate $\gamma_{t}$ is determined by Eq. (14) after replacing $f$ by $f\left(y_{t}\right)$. As it still holds that $\partial \gamma_{t} / \partial f\left(y_{t}\right)>0$, it follows that $\gamma_{t}$ is also decreasing in $y_{t}$.

Whenever the aid ratio $F_{t} / y_{t}$ and, consequently, the consumption growth rate $\gamma_{t}$ vary over time, the problem however arises that capital $k_{t}$ and output $y_{t}$ (and, hence, $p_{t}, g_{t}$ and $r_{t}$ ) do not necessarily grow at the rate $\gamma_{t}$. Moreover, capital and output growth rates can in general not be derived analytically.

The effect of foreign aid on the consumption growth rate $\gamma_{t}$ is therefore still positive and decreasing in the tax rate $\tau$, in the aid ratio $F_{t} / y_{t}$ and in the institutional quality parameter $\phi$, but it is uncertain whether the same holds true for the effect of foreign aid on capital accumulation and output growth as well.

\subsection{Endogenous institutional quality}

We assume in the baseline model that institutional quality and, hence, the share $\phi$ of public funds that rent seekers can appropriate are independent of aggregate rent seeking efforts $e$. We now discuss how our results change if the share $\phi$ increases in $e .{ }^{17}$

Since the agents' optimal rent seeking effort $e^{*}$ is a function of the share $\phi$ (see Eq. (10)), assuming that $\phi$ itself is a function of aggregate rent seeking efforts $e$ creates the possibility of multiple equilibria (see also Mauro (2004)). To illustrate this, we assume a simple functional form that allows to solve the model explicitly: $\phi=q e$ with $q \in[(1-\tau) \alpha /(\tau+f), 1]{ }^{18}$

It then follows from Eqs. (10) and $\phi=q e$ that there are two possible equilibria: A first with the agents' optimal rent seeking effort

$$
e_{1}^{*}=\frac{q(\tau+f)-(1-\tau) \alpha}{q(\tau+f)}
$$

and institutional quality $\phi_{1}^{*}=q e_{1}^{*}$, and a second with $e_{2}^{*}=0$ and $\phi_{2}^{*}=0$. We look at the first equilibrium first: Like the optimal rent seeking effort $e^{*}$ in the baseline model, $e_{1}^{*}$ also increases in the tax rate $\tau$ and the aid ratio $f$. Moreover, $e_{1}^{*}$ increases in $q$,

\footnotetext{
${ }^{16} \mathrm{~A}$ simple aid regime satisfying this condition is constant aid payments, i.e., $F_{t}=F$ for all $t$ and $y_{t}$.

${ }^{17}$ Hodler (2006) also provides a model with a rent seeking contest for windfall gains and endogenous institutional quality. His model, however, is static and focuses on resource windfalls.

${ }^{18}$ The condition $q \geq(1-\tau) \alpha /(\tau+f)$ guarantees that the first of the subsequently presented equilibria exists. 
i.e., in the impact of rent seeking on the share $\phi$ of public funds that rent seekers can appropriate. After inserting $l_{1}^{*}=1-e_{1}^{*}$ and $\phi_{1}^{*}$ in Eq. (14), it can be shown that the growth rate $\gamma$ decreases in the aid ratio $f$. Remember that the positive growth effect of aid, which is due to a rise in public goods $g_{t}$, dominates in the baseline model the negative growth effect of aid, which is due to an increase in rent seeking activities $e^{*}$. Here, however, the aid-induced increase in rent seeking lowers institutional quality, i.e., it increases $\phi$, which in turn dampens the positive effect and amplifies the negative effect. As a consequence, the negative effect dominates such that an increase in foreign aid lowers growth. ${ }^{19}$ Note that the presence of rent seeking is necessary for such a negative (net) effect of foreign aid on growth; decreasing returns to productive public goods $g_{t}$ alone are not sufficient.

In the second equilibrium, no agent engages in rent seeking activities since all agents (rightly) expect that there is no rent seeking and that institutions are thus of such high quality that appropriation from public funds is impossible. In this equilibrium, a marginal increase in foreign aid does not increase rent seeking activities and has therefore an unambiguously positive effect on growth. ${ }^{20}$

To summarize, taking the potential negative effect of rent seeking on institutional quality into account helps us to explain why foreign aid can be detrimental in some countries; but it also shows that rent seeking can be low or even absent in societies in which people trust that others do not engage in rent seeking either.

\subsection{Aid disbursing and taxation institutions}

In the baseline model, rent seekers can appropriate the share $\phi$ of the aid payments $F_{t}=f y_{t}$ and of the tax revenues $\tau y_{t}$. In reality, the quality of aid disbursing institutions and taxation institutions may however differ, e.g. because it may be easier for donors to supervise the former. We therefore assume in this section (i) that agents engaging in rent seeking activities can appropriate the share $\phi_{f}$ of $F_{t}$ and the share $\phi_{\tau}$ of $\tau y_{t}$, and (ii) that agents can allocate their time to rent seeking for aid $e_{f}$, to rent seeking for tax revenues $e_{\tau}$, and to productive activities $l=1-e_{f}-e_{\tau}$.

Solving the agents' income maximization problem (as in Section 3.3) leads to the optimal rent seeking efforts

$$
e_{f}^{*}=\frac{\phi_{f} f}{(1-\tau) \alpha+\phi_{f} f+\phi_{\tau} \tau}
$$

and

$$
e_{\tau}^{*}=\frac{\phi_{\tau} \tau}{(1-\tau) \alpha+\phi_{f} f+\phi_{\tau} \tau} \text {. }
$$

\footnotetext{
${ }^{19}$ This result is similar to those of Lane and Tornell (1996) and Tornell and Lane (1999). They show that terms of trade windfalls can lead to a voracity effect and, consequently, to lower growth rates.

${ }^{20}$ For an equilibrium with zero rent seeking to exist for all $\tau$ and $f$ (but not for the multiplicity of equilibria itself), it is necessary that $\phi=0$ if $e=0$.
} 
An increase in the aid ratio $f$ raises $e_{f}^{*}$ and reduces $e_{\tau}^{*}$. However, the rise in $e_{f}^{*}$ outweighs the reduction in $e_{\tau}^{*}$ such that total rent seeking $e^{*}=e_{f}^{*}+e_{\tau}^{*}$ remains increasing in $f$.

To compare the predictions of our baseline model and this modified version, note that rent seekers appropriate the share $\phi^{\prime} \equiv\left(\phi_{\tau} \tau+\phi_{f} f\right) /(\tau+f)$ of the total public funds $p_{t}=F_{t}+\tau y_{t}$ in the latter. Given $\phi=\phi^{\prime}$ in the baseline model, it can be shown that $\partial e^{*} / \partial f$ is higher in the baseline model than in the modified version if and only if $\phi_{f}<\phi_{\tau}$. The baseline model thus overestimates the rise in rent seeking that an aid increase causes if and only if $\phi_{f}<\phi_{\tau}$. It further underestimates the positive effect of foreign aid on productive public goods $g_{t}$ if and only if $\phi_{f}<\phi_{\tau}$. As a consequence, the baseline model underestimates the growth effect of foreign aid if aid disbursing institutions are of higher quality than taxation institutions, i.e., if $\phi_{f}<\phi_{\tau}$; while it overestimates aid effectiveness if $\phi_{f}>\phi_{\tau}$.

This result suggests that donors can raise aid effectiveness by disbursing foreign aid directly through their own aid agencies rather than trough the recipient country's treasury or other local institutions, given that their aid agencies are less prone to rent seeking than the local institutions.

\subsection{Aid conditionality}

In line with the conclusion of the World Bank (1998), we assume in the baseline model that foreign aid is fungible. In this section, we discuss how our results may change if foreign aid is provided on a conditional basis and if the donors can successfully commit to adhere to the imposed conditions.

Suppose the donors disburse aid if and only if the growth rate exceeds a certain threshold $\gamma^{\text {crit }}$, which is higher than the current growth rate $\gamma$. Unless agents couldfor some reasons outside the model-successfully coordinate on a reduction of their rent seeking efforts $e^{*}$, such a condition can only be met if the government improves the institutional quality or its tax policy, which means lowering $\phi$ or choosing a tax rate $\tau$ closer to the optimal rate $\tau^{*}$. The government may, on the one hand, have an incentive to improve the institutional quality and its tax policy if it gains sufficiently from foreign aid and faster growth. On the other hand, it may lack the willingness to implement such reforms if it benefits from the status quo. Moreover, it may lack the power to implement reforms. Given the government were able and willing to undertake the reforms necessary for the growth rate $\gamma$ to increase to at least $\gamma^{\text {crit }}$, well-designed conditional aid could be very effective.

Similarly, foreign aid that is disbursed if and only if aggregate rent seeking $e^{*}$ falls below a certain threshold $e^{\text {crit }}$ could also be very effective if the government were willing and able to strengthen institutional quality and/or to lower tax rates.

Alternatively, donors could target foreign aid at strengthening institutional quality, i.e., at reducing $\phi$. If this could be done successfully, it might also increase aid effectiveness. $^{21}$

\footnotetext{
${ }^{21}$ However, Knack's (2001) finding that aid tends to worsen bureaucratic quality and the rule of law suggests that it might be difficult to use foreign aid to strengthen institutional quality.
} 


\section{Conclusions}

In this paper, we have shown that enriching a standard growth model with foreign aid and a rent seeking contest for public funds leads to results that are consistent with the best known and the most robust empirical findings on aid effectiveness. In particular, this model suggests (i) that foreign aid works better if taxation is moderate, (ii) that the returns to aid are decreasing, and (iii) that foreign aid works better if there are institutions that limit appropriation of public funds by rent seekers-unlike the institutions in most tropical countries. Rent seeking behavior may therefore indeed be partly responsible for the poor effectiveness of foreign aid in various countries.

These results suggest some policy implications for aid donors that aim at promoting growth and development: Such donors should focus on countries with institutions that restrict excessive rent seeking, i.e., institutions that prevent large flows of aid money into the hands and onto the bank accounts of rent seekers. When supporting countries with poor institutions nevertheless, donors may be able to raise aid effectiveness by taking local authorities out of the loop and disbursing the aid themselves. Further, donors should not expect foreign aid to be very effective if given in large amounts, or to countries in which productive activities are heavily taxed.

\section{Appendix}

It follows from the Eqs. (10), (14), (17) and (18) that

$$
\frac{\partial \gamma}{\partial f}=\frac{\left[\alpha^{(3-2 \alpha)} A \Gamma\right]^{\frac{1}{(1-\alpha)}}}{(1-\alpha) \sigma}
$$

with

$$
\Gamma \equiv \frac{(1-\tau)^{(2-\alpha)}(1-\phi)^{\alpha}}{(\tau+f)^{(1-2 \alpha)}[(1-\tau) \alpha+\phi(\tau+f)]}>0 .
$$

It follows from Eq. (24) that

$$
\frac{\partial \Gamma}{\partial \tau}=\frac{-\left[(1-\tau) \alpha \Psi_{1}+\phi(\tau+f) \Psi_{2}\right] \Gamma}{(1-\tau)(\tau+f)[(1-\tau) \alpha+\phi(\tau+f)]}
$$

with

$$
\begin{aligned}
& \Psi_{1} \equiv(1-2 \alpha)(1-\tau)+(1-\alpha)(\tau+f), \\
& \Psi_{2} \equiv 2(1-\alpha)(1-\tau)+(2-\alpha)(\tau+f) .
\end{aligned}
$$

Since $\Psi_{1}>0$ and $\Psi_{2}>0$ (as $\left.\alpha<1 / 2\right)$, it holds that $\partial \Gamma / \partial \tau<0$. As Eq. (23) indicates, $\partial \Gamma / \partial \tau<0$ implies $\partial^{2} \gamma /(\partial f \partial \tau)<0$. 
Similarly,

$$
\frac{\partial \Gamma}{\partial f}=\frac{-[(1-2 \alpha)(1-\tau) \alpha+2(1-\alpha) \phi(\tau+f)] \Gamma}{(\tau+f)[(1-\tau) \alpha+\phi(\tau+f)]}<0
$$

and

$$
\frac{\partial \Gamma}{\partial \phi}=\frac{-\left\{(1-\tau) \alpha^{2}+[1-(1-\alpha) \phi](\tau+f)\right\} \Gamma}{(1-\phi)[(1-\tau) \alpha+\phi(\tau+f)]}<0,
$$

respectively, imply $\partial^{2} \gamma / \partial f^{2}<0$ and $\partial^{2} \gamma /(\partial f \partial \phi)<0$.

Acknowledgments I would like to thank two anonymous referees for their helpful comments.

\section{References}

Acemoglu, D., Johnson, S., \& Robinson, J. A. (2001). The colonial origins of comparative development: an empirical investigation. American Economic Review, 91, 1369-1401.

Ades, A., \& di Tella, R. (1997). National champions and corruption: Some unpleasent interventionist arithmetic. Economic Journal, 108, 1381-1403.

Aidt, T. S. (2003). Economic analysis of corruption: a survey. Economic Journal, 113, F632-F652.

Bardhan, P. (1997). Corruption and development: A review of issues. Journal of Economic Literature, 35 , $1320-1346$.

Barreto, R. A. (2000). Endogenous corruption in a neoclassical growth model. European Economic Review, 44, 35-60.

Barro, R. J. (1990). Government spending in a simple model of endogenous growth. Journal of Political Economy, 98, S103-S125.

Bauer, P. T. (1981). Equality, the third world, and economic delusion. Cambridge, MA: Harvard University Press.

Benhabib, J., \& Rustichini, A. (1996). Social conflict and growth. Journal of Economic Growth, 1, 125-139.

Bloom, D., \& Sachs, J. D. (1998). Geography, demography, and economic growth in Africa. Brookings Papers on Economic Activity, 2, 207-273.

Burnside, C., \& Dollar, D. (2000). Aid, policies, and growth. American Economic Review, 90, 847-868.

Collier, P., \& Dollar, D. (2002). Aid allocation and poverty reduction. European Economic Review, 45, $1-26$.

Dalgaard, C.-J., \& Hansen, H. (2001). On aid, growth and good policies. Journal of Development Studies, $37,17-41$.

Dalgaard, C.-J., Hansen, H., \& Tarp, F. (2004). On the emprics of foreign aid and growth. Economic Journal, 114, F191-F216.

Easterly, W. (2001). The elusive quest for growth: economists' adventures and misadventures in the tropics. Cambridge: MIT Press.

Easterly, W. (2003). Can foreign aid buy growth? Journal of Economic Perspectives, 17, $23-48$.

Easterly, W., \& Levine, R. (2003). Tropics, germs, and crops: How endowments influence economic development. Journal of Monetary Economics, 50, 3-39.

Easterly, W., Levine, R., \& Roodman, R. (2004). New data, new doubts: A comment on burnside and Dollar's “Aid, Policies, and Growth" (2000). American Economic Review, 94, 774-780.

Ehrlich, I., \& Lui, F. T. (1999). Bureaucratic corruption and endogenous economic growth. Journal of Political Economy, 107, 270-293.

Ellis, C. J., \& Fender, J. (2006). Corruption and transparency in a growth model. International Tax and Public Finance, 13, 115-149.

Feyzioglu, T., Swaroop, V., \& Zhu, M. (1998). A panel data analysis of the fungibility of foreign aid. World Bank Economic Review, 12, 29-58.

Gallup, J. L., Sachs, J. D., \& Mellinger, A. D. (1998). Geography and economic development. NBER Working Paper 6849. 
Gelb, A., Knight, J. B., \& Sabot, R. H. (1991). Public sector employment, rent seeking and economic growth. Economic Journal, 101, 1186-1199.

Grossman, H. I. (2001). The creation of effective property rights. American Economic Review, 91, 347-352.

Hansen, H., \& Tarp, F. (2001). Aid and growth regressions. Journal of Development Economics, 64, 547570 .

Hodler, R. (2006). The curse of natural resources in fractionalized countries. European Economic Review, 50, 1367-1386.

Knack, S. (2001). Aid dependence and the quality of governance: Cross-country empirical tests. Southern Economic Journal, 68, 310-329.

Knack, S., \& Keefer, P. (1995). Institutions and economic performance: Cross-country tests using alternative institutional measures. Economics and Politics, 7, 207-227.

Lane, P. R., \& Tornell, A. (1996). Power, growth and the voracity effect. Journal of Economic Growth, 1, 213-241.

Lensink, R., \& White, H. (2001). Are there negative returns to aid? Journal of Development Studies, 37, 42-65.

Mankiw, N. G., Romer, D., \& Weil, D. N. (1992). A contribution to the empirics of economic growth. Quarterly Journal of Economics, 107, 407-437.

Mauro, P. (1995). Corruption and growth. Quarterly Journal of Economics, 110, 681-712.

Mauro, P. (2004). The persistence of corruption and slow economic growth. IMF Staff Papers, 51, 1-18.

Murphy, K. M., Shleifer, A., \& Vishney, R. W. (1991). The allocation of talent: Implications for growth. Quarterly Journal of Economics, 106, 503-530.

Rodrik, D., Subramanian, A., \& Trebbi, F. (2004). Institutions rule: The primacy of institutions over geography and integration in economic development. Journal of Economic Growth, 9, 131-165.

Roodman, D. (2004). The anarchy of numbers: aid, development, and cross-country empirics. Washington: Center for Global Development, Working Paper 32.

Sachs, J. D. (2001). Tropical Underdevelopment. NBER Working Paper 8119.

Sachs, J. D. (2003). Institutions don't rule: Direct effects of geography on per capita income. NBER Working Paper 9490.

Sturzenegger, F., \& Tommasi, M. (1994). The distribution of political power, the costs of rent-seeking, and economic growth. Economic Inquiry, 32, 236-248.

Svensson, J. (2000). Foreign aid and rent-seeking. Journal of International Economics, 51, 437-461.

Tornell, A. (1997). Economic growth and decline with endogenous property rights. Journal of Economic Growth, 2, 219-250.

Tornell, A., \& Lane, P. R. (1999). The voracity effect. American Economic Review, 89, 22-46.

Tornell, A., \& Velasco, A. (1992). The tragedy of the commons and economic growth: Why does capital flow from poor to rich countries? Journal of Political Economy, 100, 1208-1231.

Tullock, G. (1980). Efficient rent seeking. In J. M. Buchanan, R. D. Tollison, \& G. Tullock (Eds.), Toward a Theory of the Rent Seeking Society. College Station: Texas A\&M University Press.

World Bank. (1998). Assessing aid: what works, what doesn't and why. Oxford: Oxford University Press. 